\title{
Editorial: Advancements in Biomass Feedstock Preprocessing: Conversion Ready Feedstocks
}

\author{
J. Richard Hess ${ }^{1 *}$, Allison E. Ray ${ }^{1 *}$ and Timothy G. Rials ${ }^{2 *}$ \\ ${ }^{1}$ Idaho National Laboratory, Idaho Falls, ID, United States, ${ }^{2}$ The Center for Renewable Carbon, The University of Tennessee, \\ Knoxville, Knoxville, TN, United States
}

Keywords: biomass variability, conversion-ready feedstocks, preprocessing, blending, fractionation, sorting, resource diversity, integrated biorefineries

\section{Editorial on the Research Topic}

Advancements in Biomass Feedstock Preprocessing: Conversion Ready Feedstocks

\section{INTRODUCTION}

The success of lignocellulosic biofuels and biochemical industries depends on an economic and reliable supply of biomass that meets conversion quality standards. However, research and development have historically focused on the utilization of lignocellulosic biomass resources without consideration of their high variations in physical and chemical characteristics and potential supply risks in terms of availability and affordability (Ray et al., 2017). This Research Topic explored strategies aimed at enabling supply-chain improvements in biomass quality and consistency through preprocessing operations like blending, sorting, leaching, drying, and other quality-management approaches for development of "conversion-ready" lignocellulosic feedstocks for production of biofuels and bio-products. A conversion-ready feedstock refers to an industrialscale feedstock resource with chemical and physical properties that meet the design specifications of biorefinery handling and conversion systems.

Variability has proven a formidable challenge to integrated biorefineries, impeding continuous operation and reducing product yields required for economical production of lignocellulosic biofuels and chemicals at scale (U. S. Department of Energy, 2016). Simple or minimalistic biomass supply systems (herein referred to as "conventional") that deliver field-run biomass to the biorefinery, while minimizing operating costs, do not ensure that biomass resources consistently meet feedstock quality requirements. Conventional supply systems lack the preprocessing capabilities necessary to produce feedstocks with consistent physical and chemical properties that are compatible with conversion processes (Lamers et al., 2015). Further, the utility of conventional systems has been limited to high-yield regions like the U.S. Corn Belt (Argo et al., 2013). Direct coupling of conventional biomass supply systems with sophisticated conversion processes is further complicated by the unique challenges of bulk-solids behavior in particulate systems (Bell, 2005) and the cohesive nature of compressible, elastic biomass solids (Hernandez et al., 2017; Xia et al., 2019). Recent reports indicate the operability of biorefining processes and process models remain at less than $50 \%$ due to the variable physicochemical properties of biomass (U. S. Department of Energy, 2016).

As the bioeconomy grows, the variability inherent to biomass cannot be managed solely by passive supply systems (Kenney et al., 2013; Searcy et al., 2015). Recognition and understanding of the magnitude of biomass variability and uncertainty (Williams et al., 2016) must be balanced with the cost of failing to design feedstock supply systems that can manage variations. Targeted preprocessing strategies aim to develop stable, cost-effective and quality-controlled biomass supply 
systems ( $\mathrm{Li}$ et al., 2016). For instance, blending and densification approaches (Tumuluru et al., 2011; Ray et al., 2017; Ou et al., 2018; Narani et al., 2019) have shown promise for diversifying biomass resources to enable supply-chain resilience for the development of consistent, high-quality feedstocks and move toward advanced feedstock-supply systems.

The significance of feedstock quality on overall processing efficiency and expense has been recognized for some time; however, affordable solutions to the range of challenges presented by the biomass-to-feedstock operation have been slow to emerge. Recent work in government and academic laboratories, as well as industrial facilities has identified more problematic areas and provided direction for innovation to mitigate many of those longrunning challenges. This special issue is a collection of 23 articles that report on strategies that enable supply-chain improvements in biomass quality and consistency to produce conversion-ready feedstocks for biorefining.

\section{INTEGRATED PREPROCESSING}

Integrated preprocessing techniques represent the majority of the collection. Active biomass-preprocessing controls, like drying, sorting, sizing, fractionating, leaching, densifying, etc., integrated into biomass supply systems can reduce complications in downstream conversion systems. The collection discusses six preprocessing techniques for generation of conversionready feedstocks. This issue highlights research that employs biomass preprocessing through fractionation, leaching, sorting, blending and sizing processes to enhance material quality for downstream conversion. Williams et al. and Kim et al. both address how the separation of biomass components can optimize conversion. Therasme et al. explore leaching as a preprocessing step to improve biomass quality and create co-products, and Williams et al. report the benefits of both air classification and separation of biomass materials for downstream conversion. The second of the techniques addressed is the blending of feedstocks. Edmunds et al. described mixing different biomass types to mitigate rheological-and compositionalvariability challenges seen in individual biomass resources. The third technique discussed is preprocessing and pretreatment of biomass materials for conversion. Brandt et al. address mechanical biomass preprocessing methods, and Williams et al. report on chemical methods to prepare the biomass materials for conversion. Biomass densification, the fourth technique, is addressed by Dien et al., who report on preprocessing and pelletizing techniques that reduce supply-system losses. Storage impacts on biomass quality and downstream conversion are addressed in work from Essien et al., Essien and Richard, Wendt et al., and Wendt et al.; all four papers discuss the effectiveness of wet storage to preserve and improve biomass materials for conversion. High-throughput and rapid methods for assessing biomass attributes and their behavior are also explored and represent tools that advance understanding and development of conversion-ready feedstocks (Coffman et al.; Decker et al.).

\section{SUSTAINABLE AND EFFICIENT FEEDSTOCK SUPPLY-TO-CONVERSION PRACTICES}

As solutions to biomass variability issues are introduced, environmental and economic impacts become an issue of concern. The collection discusses research on creating moresustainable biorefining facilities and producing conversionready feedstocks from recyclables. Martinkus et al. address the cost advantage of assessing existing industrial facilities for repurposing to biorefinery applications. Other papers include discussions of how to leverage recycled materials as biomass feedstocks (Paritosh et al.; Xu et al.) and the viability of recycling materials already used in preprocessing (Chen et al.).

\section{IMPACT OF WEATHER AND RELATED EXTERNAL FACTORS}

Environmental and other external factors that impact biomass variability and conversion processes are also considered in the collection. Addressing external issues-including equipment wear from soil-accumulated inorganics in biomass (Lacey et al.), challenges in the supply-chain structure (Sharma et al.), harvesting timelines and appropriate equipment selection (Daniel et al.), and weather factors (Hoover et al.; Ong et al.)offer insights to process changes that could be implemented to improve the viability of biomass feedstock supply chains.

\section{CONCLUSION}

A paradigm shift is needed from biorefinery designs using raw biomass resources to advanced feedstock-supply systems that deliver commercial-scale biomass feedstocks that are conversion ready (Searcy et al., 2015). There is a need to fully recognize the magnitude of variability and uncertainty in biomass resources, as well as the cost of failing to design feedstock-supply systems that can mitigate that variability and uncertainty. As the recognition and need for conversion-ready biomass feedstocks increase, the research presented in this collection will prove increasingly beneficial. Considering conversion-ready feedstocksupply systems for biorefining allows greater opportunities to manage supply risks, including feedstock system designs that may incorporate the biomass preprocessing techniques presented in this collection. Such feedstock supply systems will provide value-added upgrading of the biomass to increase its convertibility and market fungibility. Taken together, these papers present relevant research that will enable stakeholders to better navigate the range of challenges related to consistently and economically producing conversion-ready feedstocks derived from lignocellulosic biomass on a commercial scale.

\section{AUTHOR CONTRIBUTIONS}

All authors listed have made a substantial, direct and intellectual contribution to the work, and approved it for publication. 


\section{FUNDING}

This research was supported by the U.S. Department of Energy, Office of Energy Efficiency and Renewable Energy, Bioenergy Technologies Office, under DOE Idaho Operations

\section{REFERENCES}

Argo, A. M., Tan, E. C. D., Inman, D., Langholtz, M. H., Eaton, L. M., Jacobson, J. J., et al. (2013). Investigation of biochemical biorefinery sizing and environmental sustainability impacts for conventional bale system and advanced uniform biomass logistics designs. Biofuels Bioprod. Biorefin. 7, 282-302. doi: 10.1002/bbb.1391

Bell, T. A. (2005). Challenges in the scale-up of particulate processes-an industrial perspective. Powder Technol. 150, 60-71. doi: 10.1016/j.powtec.2004.11.023

Hernandez, S., Westover, T. L., Matthews, A. C., Ryan, J. C. B., and Williams, C. L. (2017). Feeding properties and behavior of hammer- and knife-milled pine. Powder Technol. 320, 191-201. doi: 10.1016/j.powtec.2017.07.002

Kenney, K. L., Smith, W. A., Gresham, G., and Westover, T. L. (2013). Understanding biomass feedstock variability. Biofuels 4, 111-127. doi: $10.4155 /$ bfs. 12.83

Lamers, P., Tan, E. C. D., Searcy, E. M., Scarlata, C. J., Cafferty, K. G., and Jacobson, J. J. (2015). Strategic supply system design - a holistic evaluation of operational and production cost for a biorefinery supply chain. Biofuels Bioprod. Biorefin. 9, 648-660. doi: 10.1002/bbb.1575

Li, C., Aston, J. E., Lacey, J. A., Thompson, V. S., and Thompson, D. N. (2016). Impact of feedstock quality and variation on biochemical and thermochemical conversion. Renew. Sustain. Energy Rev. 65, 525-536. doi: 10.1016/j.rser.2016.06.063

Narani, A., Konda, N. V. S. N.M., Chen, C.-S., Tachea, F., Coffman, P., Gardner, J., et al. (2019). Simultaneous application of predictive model and least-cost formulation can substantially benefit biorefineries outside Corn Belt in United States: a case study in Florida. Bioresour. Technol. 271, 218-227. doi: 10.1016/j.biortech.2018. 09.103

Ou, L., Luo, G., Ray, A., Li, C., Hu, H., Kelley, S., et al. (2018). Understanding the impacts of biomass blending on the uncertainty of hydrolyzed sugar yield from a stochastic perspective. ACS Sustain. Chem. Eng. 6, 10851-10860. doi: 10.1021/acssuschemeng.8b02150.

Ray, A. E., Li, C., Thompson, V. S., Daubaras, D. L., Nagle, N. J., and Hartley, D. S. (2017). "Biomass blending and densification: impacts on feedstock supply and biochemical conversion performance," in Biomass Volume Estimation and Valorization for Energy, ed J. S. Tumuluru (London: InTechOpen). p. 341-359.
Office Contract DE-AC07- 05ID14517. Dr. Rials would like to acknowledge support for this project provided by the Tennessee Agricultural Experiment Station and AgResearch. The authors wish to acknowledge Leslie Ovard, Amanda Sant, and Jessica McCord for editorial support.

Searcy, E., Lamers, P., Hansen, J., Jacobson, J., Hess, J. R., and Webb, E. (2015). Advanced Feedstock Supply System Validation Workshop - Summary Report. Golden, CO: US Department of Energy [DOE] Bioenergy Technologies Office [BETO]; Idaho National Laboratory [INL]; Oak Ridge National Laboratory [ORNL].

Tumuluru, J. S., Wright, C. T., Hess, J. R., and Kenney, K. L. (2011) A review of biomass densification systems to develop uniform feedstock commodities for bioenergy application. Biofuel Bioprod. Bioresour. 5, 683-707. doi: $10.1002 /$ bbb. 324

U. S. Department of Energy (2016). Biorefinery Optimization Workshop Summary Report. Washington, DC: Office of Energy Efficiency and Renewable Energy Bioenergy Technologies Office.

Williams, C. L., Westover, T. L., Emerson, R. M., Tumuluru, J. S., and Li, C. (2016). Sources of biomass feedstock variability and the potential impact on biofuels production. Bioenergy Res. 9, 1-14. doi: 10.1007/s12155-015-9694-y

Xia, Y., Lai, Z., Westover, T., Klinger, J., Huang, H., and Chen, Q. (2019). Discrete element modeling of deformable pinewood chips in cyclic loading test. Powder Technol. 345, 1-14. doi: 10.1016/j.powtec.2018.12.072

Disclosure: The views and opinions of the authors expressed herein do not necessarily state or reflect those of the United States Government or any agency thereof. Neither the United States Government nor any agency thereof, nor any of their employees, makes any warranty, expressed or implied, or assumes any legal liability or responsibility for the accuracy, completeness, or usefulness of any information, apparatus, product, or process disclosed, or represents that its use would not infringe privately owned rights.

Conflict of Interest: The authors declare that the research was conducted in the absence of any commercial or financial relationships that could be construed as a potential conflict of interest.

Copyright (c) 2019 Hess, Ray and Rials. This is an open-access article distributed under the terms of the Creative Commons Attribution License (CC BY). The use, distribution or reproduction in other forums is permitted, provided the original author(s) and the copyright owner(s) are credited and that the original publication in this journal is cited, in accordance with accepted academic practice. No use, distribution or reproduction is permitted which does not comply with these terms. 